\title{
Fatigue Analysis of Actuators with Teflon Impregnated Coating-Challenges in Numerical Simulation
}

\author{
Zhuming Bi ${ }^{1, *(1)}$, Bongsu Kang ${ }^{1}$ and Puren Ouyang ${ }^{2}(\mathbb{D}$ \\ 1 Department of Civil and Mechanical Engineering, Purdue University Fort Wayne, \\ Fort Wayne, IN 46805, USA; kangb@pfw.edu \\ 2 Department of Aerospace Engineering, Ryerson University, Toronto, ON M5B 2K3, Canada; \\ pouyang@ryerson.ca \\ * Correspondence: biz@pfw.edu
}

check for updates

Citation: Bi, Z.; Kang, B.; Ouyang, P. Fatigue Analysis of Actuators with Teflon Impregnated Coating-Challenges in Numerical Simulation. Actuators 2021, 10, 82. https://doi.org/ $10.3390 /$ act10040082

Academic Editors: Kash Khorasani and Giorgio Olmi

Received: 16 February 2021

Accepted: 14 April 2021

Published: 18 April 2021

Publisher's Note: MDPI stays neutral with regard to jurisdictional claims in published maps and institutional affiliations.

Copyright: (c) 2021 by the authors. Licensee MDPI, Basel, Switzerland. This article is an open access article distributed under the terms and conditions of the Creative Commons Attribution (CC BY) license (https:// creativecommons.org/licenses/by/ $4.0 /)$.

\begin{abstract}
Actuators are essential components for motion in machines, and warranty service lives are basic specifications of actuators. However, fatigue damage or wear of actuators are very complex and related to many design factors, such as materials properties, surface conditions, loads, and operating temperature. Actuator manufacturers still rely heavily on physical experiments to determine the fatigue lives of actuators. This paper investigates the state-of-the-art of using numerical simulations for fatigue analysis of mechanical actuators. Failure criteria of machine elements are discussed extensively; existing works on using finite element methods for machine element designs are examined to (1) explore the feasibility of using a numerical simulation for fatigue analysis and (2) discuss the technical challenges in practice. Moreover, a systematic procedure is suggested to predict fatigue lives of mechanical actuators with Teflon impregnated hard coatings. A virtual fatigue analysis allows for optimizing a mechanical structure, reducing design verification costs, and shortening the development time of actuators.
\end{abstract}

Keywords: actuators; fatigue analysis; wears; numerical simulation; finite element analysis; virtual design; simulation-based optimization

\section{Introduction}

The manufacturing industry has continuously advanced since steam engines were introduced to mechanize manual operations in the 1700s, and motors and actuators have become important machine components in mechanizing and automating various manufacturing processes [1]. Since the advancement of manufacturing technologies can be measured by the degree of automation where more and more automated machines and robots are adopted to substitute humans, there is an increasing demand for developing cost-effective approaches to design, manufacturing, and testing of complex machine components, including actuators [2].

Actuators are essential elements in implementing the motions of machines. The design of an actuator is complex since it has functional requirements from many aspects, such as type and range of motion, workload, maximum speed and acceleration, precision, and repeatability. In addition, an actuator must have information about its service life. However, with very few exceptions [3-7], the analysis of service lives or fatigue lives on moving parts still heavily rely on tests [8-16]. While an experimental approach leads to a reliable result, it is disadvantageous in a sense that (1) the machine element must be physically available; (2) a testing system needs to be developed for a specific test; (3) one experimental result is applicable only under certain operational conditions, and a large number of experiments may be required for a broad application of actuators; (4) experiments take a long time and involve in a high cost for product development [17]. It is desirable to analyze fatigue lives of moving elements to compare more design options, reduce the cost of tests, and shorten the product development cycle. 
Nowadays, manufacturers of robotic components depend mostly on experiments to determine the fatigue characteristics of their products, and a systematic numerical approach to predict the fatigue lives of actuators is lacking [2]. This paper aims to investigate the stateof-the-art on fatigue life prediction of machine components to identify technical difficulties and develop a workflow for fatigue life prediction using numerical methods; the fatigue analysis for end-effectors with Teflon impregnated coating is especially considered. The rest of this paper is organized as follows. Section 1 discusses the measures of fatigue damage and failure and compares three common methods for the assessment of fatigue life. Section 3 rationalizes the need for the coating on contact surfaces of actuators, and an example of an actuator with Teflon-impregnated aluminum alloy is presented. Section 4 summarizes the existing studies on fatigue analysis by finite element methods. Section 5 discusses the technical challenges involved in virtual fatigue analysis. Section 6 presents a workflow for virtual fatigue analysis with proposed solutions to the identified challenges. Section 7 summarizes our work and contributions.

\section{Criteria for Fatigue Damage Failure}

Fatigue results from the damage caused by dynamic loading. Differing from a yield or fracture failure when the stress exceeds material strength, a material may fail by fatigue at any stress level [18]. Fatigue progresses sequentially in three phases from initiation, growth, and finally to fracture. The fatigue strength of materials depends on many factors such as loads, number of loading cycles, surface conditions, geometric features, and temperatures $[17,19]$. Fatigue damages are measured by three criteria: strain-life, stresslife, and linear-elastic fracture mechanics (LEFM).

\subsection{Strain-Life}

A strain-life curve gives a good explanation about how fatigue damage is initialized and developed [20]. Dynamic stress at any amplitude level leads to certain plastic strain, which cannot be recovered when the stress is removed. Both elastic and plasmatic deformations under a dynamic load contribute to the growth of the total strain, and the total strain can be estimated by the Manson-Coffin-Basquin's equation (also called the Morrow's equation) as:

$$
\frac{\Delta \varepsilon}{2}=\frac{\sigma_{F}^{\prime}}{E}(2 N)^{b}+\varepsilon_{F}^{\prime}(2 N)^{c}
$$

where $\Delta \varepsilon$ is total strain; $E$ is the elastic modulus; $2 N$ is the number of the cycles of dynamic load; $b$ and $c$ are the slopes of elastic and plastic strain lines, respectively (see Figure $1 \mathrm{~b}$ ); $\sigma_{F}^{\prime}$ and $\varepsilon_{F}^{\prime}$ are fracture stress and strain under a static load, respectively. While a strain-life explains the mechanism of fatigue damage growth, it meets some technical challenges in practice due to (1) the difficulty in measuring total strain and (2) the scarcity of data for the impact of geometric discontinuities on strain-life [21].

\subsection{Linear Elastic Fracture Mechanics (LEFM)}

Fatigue damage may present as cracks; therefore, the initialization and growth of fatigue damage are measured by crack size in linear elastic fracture mechanics (LFEM) [22]. According to LFEM, the fatigue growth rate depends on the applied stress. Assuming the minimal visible size of the crack is $a_{i}$, the growth rate of the crack is related to stress by,

$$
\frac{d a}{d N}=C\left(\Delta K_{I}\right)^{m}=C(\beta \Delta \sigma \sqrt{\pi a})^{m}
$$

where $a$ is the size of the crack; $N$ is the repeated cycles of load; $\beta$ is a geometric factor for stress intensity $[17,20] ; C$ and $m$ are empirical coefficients determined by the materials; 
$\Delta K_{I}$ and $\Delta \sigma$ are the changes of stress intensity and stress in given cycles $\Delta N$. Applying integration over Equation (2) gives the fatigue life $N_{f}$ as,

$$
N_{f}=\frac{1}{C} \int_{a_{i}}^{a_{f}} \frac{d a}{(\beta \Delta \sigma \sqrt{\pi a})^{m}}
$$

where $a_{f}$ is the crack size at the fracture. Since the stress intensity factor $\beta$ is a function of crack size $a$, some special software tools, such as FLAGRO, were used to estimate the fatigue life of products [23]. The use of LFEM in fatigue analysis demanded some essential data, such as crack types and characteristics of dynamic loads.

\subsection{Stress-Life}

The fatigue damage of a material is caused by a stress applied to the material, and a stress-life curve measures the fatigue damage based on the stress level and number of loading cycles. Accordingly, the stress limit that corresponds to the fatigue fracture in a specified number of loading cycles is defined as the fatigue strength. Differing from a yield strength or tensile strength, fatigue strength is a function of the number of loading cycles. When a fully reversed load is applied, fatigue strength $\left(S_{f}^{\prime}\right)$ is related to the number of loading cycles $(N)$ as [20],

$$
S_{f}^{\prime}=\frac{\left(f S_{u t}\right)^{2}}{S_{e}} N^{\left(-\frac{1}{3}\right) \log \left(\frac{f S_{u t}}{S_{e}}\right)}
$$

where $f$ is a fraction factor of the fatigue strength when $N=10^{3} ; S_{u t}$ and $S_{e}$ are the ultimate tensile strength and endurance limit, respectively. When the load is not fully reversed, it is characterized by its mean stress $\left(\sigma_{m}\right)$ and alternative stress $\left(\sigma_{a}\right)$, and equivalent fatigue damage can be assessed by the Gerber line, Soderberg line, Goodman line, and ASMEelliptic line shown in Table 1, respectively [24].

Table 1. Equivalent fatigue damages with mean and alternating stresses.

\begin{tabular}{cc}
\hline Fatigue Criteria & Equations \\
\hline Goodman line: & $\sigma_{a} / S_{e}+\sigma_{m} / S_{u t}=1 / n$ \\
Soderberg line: & $\sigma_{a} / S_{e}+\sigma_{m} / S_{y}=1 / n$ \\
Gerber line: & $n \sigma_{a} / S_{e}+\left(n \sigma_{m} / S_{u t}\right)^{2}=1$ \\
ASME-elliptic: & $\left(n \sigma_{a} / S_{e}\right)^{2}+\left(n \sigma_{m} / S_{u t}\right)^{2}=1$ \\
\hline
\end{tabular}

\subsection{Selection of Fatigue Analysis Methods}

All of the three methods mentioned above are used in the assessment of the fatigue damage of a product. However, fatigue analysis methods based on strain-life and LEFM require acquiring more data from physical products, which becomes impractical in virtual design [25]. Therefore, the stress-life method is most popular and widely used in numerical simulation for fatigue analysis of products. In using the stress-life method, the required inputs are (1) the characterized loads and (2) fatigue stress-strain curve (S-N curve) subjected to a fully reversed load.

\section{Fatigues by Wears and Coatings}

Over $90 \%$ of machine elements ultimately fail by fatigue. It is particularly true for moving parts that endure cyclic loading in their applications. Fatigue damage of an actuator presents as wear at contact surfaces, and thus its surface hardness and wear resistance determine the fatigue damage. Traditional engineering materials, such as aluminum alloys, have limited hardness and wear resistance for prolonged fatigue life. To improve the fatigue life of a moving part, a coating is usually applied to contact surfaces to reduce friction, enhance hardness, and improve wear and corrosion resistance [26].

Coatings on moving parts help in reducing friction and wear at contact surfaces. The main parts in an actuator involve relative motion and friction at contact surfaces and 
bring some adverse effects such as heat-induced thermal expansion and shortened fatigue life. Fatigue analysis of an actuator requires the raw material data of wear at high-cycle operations to reduce friction, decrease emission, and prolong the life of the actuator [27]. In this section, an actuator consisting of Teflon impregnated hard coated aluminum parts is used as a pilot system to discuss the effect of coating on fatigue life.

\subsection{Aluminum Alloys as Substrates}

Aluminum alloys have an excellent weight-to-strength ratio and good manufacturability, which are ideal for robotic components [19]. For example, 6XXX aluminum alloy has a good balance of ductility and fatigue strength [28]. The material properties of 6XXX families are resistant to industrial environments with good corrosion resistance and weldability.

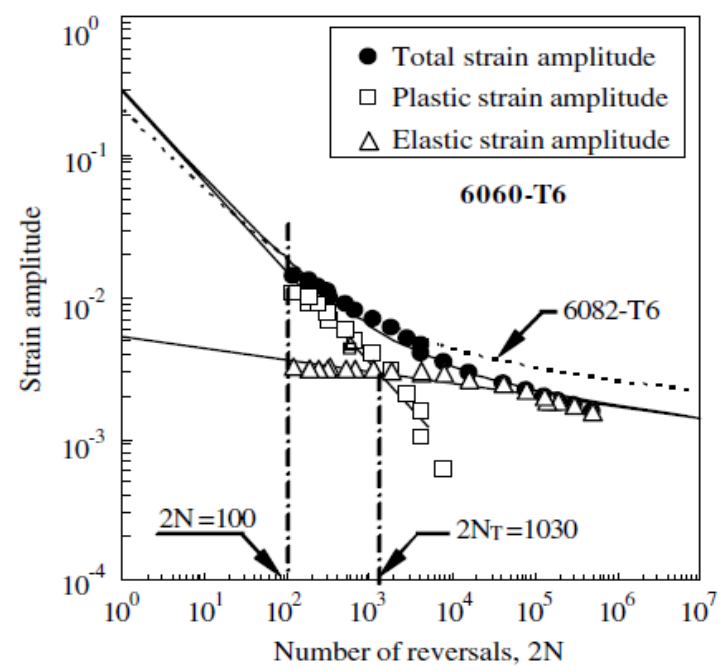

Figure 1. Stress vs. number of reversals of 6060-T6 alloy [29].

Borrego et al. [29] conducted low-cycle fatigue tests for two AlMgSi aluminum alloys (6082-T6 and 6060-T6 alloys) with different chemical compositions using standard round specimens and tube specimens, and Figure 1 showed the relation of stress and number of reversals of 6060-T6 alloy. Ochi et al. [30] and Yamamoto et al. [31] performed rotary bending fatigue tests to investigate the impact of the friction-welding process on the fatigue strength of 6061-T6 aluminum alloy. Alcoa [32] characterized tensile strength, hardness, and shear strength of Alloy 6061 under different tempering solutions. Fatigue data on 6061-T6 aluminum alloy are available from the literature [31-34]. In particular, Yahr (1993) collected the data from different sources and defined its S-N characteristics, as shown in Figure 2.

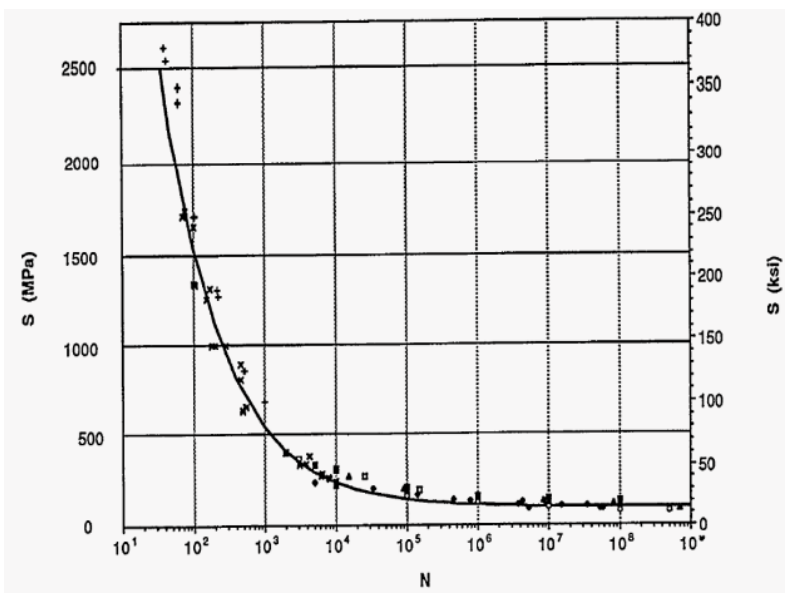

Figure 2. Fit to fully reversed 6061-T6 fatigue data [34]. 


\subsection{Polytetrafluoroethylene (PTFE) as Coatings}

Polytetrafluoroethylene (PTFE) is a synthetic fluoropolymer of tetrafluoroethylene. It is a high-molecular-weight compound consisting of carbon and fluorine. The best-known brand name of PTFE is Teflon by DuPont. The properties of typical Teflon have been provided by a number of sources, such as [35]. It is resistant to almost every chemical and solvent, and its surface is so slippery that virtually nothing would stick to it [36,37]. Due to its unique molecular and morphological structure, PTFE has one of the lowest coefficients of friction against any solid. In addition, PTFE could form a third-body transfer film when it is sliding over a hard surface [38]. PTFE has been widely used as an engineering plastic due to its relatively chemically inert nature, low friction coefficient, and outstanding thermal stability. Gong et al. [39] indicated that the wear that occurred to PTFE in the sealing interface could be characterized by abrasion and adhesion after the run-up stage; the thermal deformation and fatigue wear could be major factors causing rapid wear at contacts. Akdogan et al. [40,41] assessed the performance of steel substrates coated with PTFE impregnated aluminum bronze or molybdenum. It showed an outstanding performance of wear and surface fatigue resistance in rolling line contact. McCook et al. [42] conducted the nano-indentation test and obtained an average coating modulus of $3 \mathrm{GPa}$ and a Poisson ratio of 0.4 . The mechanical properties of polymers were significantly improved by the addition of fiber and particle reinforcement. Gan et al. [43] discussed the role of PTFE as a filler in fatigue fracture mechanisms. The target composites were a silica particle filled with PTFE and a glass fiber filled with PTFE. The fatigue data revealed that the crack speed of the first type was much lower than that of the second type. The fatigue life of the particle-base materials was almost four times higher than that of the fiber-based material. Aderikha and Shapovalov [44] studied the effect of PTFE on the tribological behavior of the composites in mechanical components. Differences in surface properties of the fillers were found to determine the molecular structures and affect mechanical properties and wear. The wear of low-filled PTFE-carbon composites was dominated by the delamination and wear resistance varied with the structure of composites. The fatigue life of PTFE, as well as factors affecting fatigue, have been investigated by a number of researchers [45-48]. For example, Wang et al. [49] discussed the formation of the transfer film of PTFE on 2024Al surface. Tribological properties of these transfer films were tested, and it was found that a uniform and continuous film prolonged the fatigue life.

\subsection{Coating over Aluminum Alloys}

In actuators, low strength and poor wear resistance can be alleviated by coating [50]. Anodizing is a well-known electrolytic process to produce controlled columnar growth of amorphous aluminum oxide on the surface of aluminum alloy. Anodizing enhances wear and corrosion resistance [51]. However, anodizing adversely affected the fatigue life of the base aluminum alloy due to the brittle and porous nature of the oxide layer and residual stress induced by anodization [52-54]. Other coating techniques include painting, coatings, chromate conversion coating, hexavalent-chromium-based conversion coatings (HCCC), such as electrolytic hard chromium (EHC) plating and chromic acid anodizing (CAA), physical vapor deposition (PVD), and chemical vapor deposition.

Friction is governed by the properties of contact surfaces. Hence, the friction and wear performance of a machine element is directly affected by the coating method. Surface engineering manipulates the surface details of a moving part to improve its tribological performance. It includes the use of thin coating, changing the surface topography, or increasing the surface hardness by case hardening or nitriding [55]. Friction is related to the entire tribosystem consisting of two contacting objects and material properties, intermediate materials, loads, motions, and environmental conditions, such as temperature, pressure, and humidity. The wear of an object can be abrasive wear when material is torn away by hard or sharper edged particles, adhesive wear when two tribologically active surfaces form an intimate adhesive bond, surface fatigue from repetitive mechanical loads leading to crack formation and propagation, and tribo-oxidation involving a chemical 
reaction at the tribological contact. Therefore, the benefits of surface coating are: (1) longer service life, (2) ability to tolerate greater loads, (3) easiness and low cost of maintenance, (4) environmental gains and conservation of resources, (5) improved response in kinetic systems, (6) lower energy consumption, (7) resistance to corrosion, (8) close tolerance, and (9) use of low-cost base materials. Coating helps aluminum alloy substrates resist friction and wear; however, it reduces the fatigue strength of substrates [24,56-58]. The fatigue life of substrates is affected by the following factors:

- Types and processes of surface treatments: Murakami [59] adopted the ultrasonic nanocrystal surface modification (UNSM) technology for the surface treatment of aluminum alloys. This UNSM technology increased fatigue strength by $50 \%$, surface hardness by $40 \%$, and reduced the surface roughness by a significant amount. Ziemian et al. [54] discussed the effects of the coating process on crack initiation subject to cyclic loading on A12024 alloy. The results showed that the deposition of cold-sprayed coating could improve the fatigue strengths in contrast to other coating methods. Similarly, Puchi-Cabrera et al. $[53,60]$ conducted the fatigue experiments on 7075-T6 aluminum alloy coated with WC-12Co or WC-10Co-4Cr by high velocity oxygen fuel spray. The coatings by spray led to a significant increase in fatigue strength of the substrate. Its potential was in replacing electrolytic hard chromium plating in aircraft applications. Baragetti and Terranova [61] investigated various process parameters in PVD on residual stresses and fatigue life of steel and aluminum alloys. Baragetti et al. [62] compared the fatigue performance of different coating materials including DLC, SiOx, and WC/C by CVD or PVD processes. Only WC/C was found to improve the fatigue life while the rest of the coating methods reduced the fatigue life. Genel [63] looked into the fatigue life under corrosion. Experiments were conducted to compare the fatigue behavior of bare and anodic oxide coated 7075-T6 alloy in air and 3.5\% NaCI solution. The presence of corrosive attack reduced fatigue performance of the alloy drastically. Examinations on the surfaces of the corrosion-fatigued specimens revealed that cyclic loading stimulated corrosion pitting. Wu et al. [64] performed an FEA analysis to investigate the impact of coating thickness on stress distribution for steel substrate with multilayer ceramic coatings (hot dipping aluminum and plasma electrolytic oxidation) subject to normal pressure load. They found that the surface tensile stress was mainly affected by the thickness ratio of the aluminum layer when the total thickness of the coating was kept constant.

- Imperfection in substrates and interfaces: Although the exact cause of fatigue degradation of coated aluminum alloy has not been clearly understood, it is generally agreed that stress concentration at micro-imperfections (micro-cracks) should be the main factor. Under fluctuating loads, the base metal at those defects loses its plasticity, which leads to the propagation of local cracks and reduces the effective area until the applied stress exceeds the yield strength and causes failure [56]. Nanninga [19] indicated that four main factors affecting the fatigue life of extruded aluminum were extrusion microstructure (grain size, aspect ratio, precipitate structure and texture), seam welds, charge welds, and die lines. Person [65] specifically investigated the fatigue life of aluminum alloy weld, and he proved that joint geometry had the greatest effect on fatigue strength. Ambriz et al. [66] conducted tests and concluded that the process of fusion welding on 6061-T6 led to a significant loss of mechanical strength and the fatigue strength defined by the crack growth on the substrates. Wasekar et al. [67] evaluated the influence of microarc oxidation (MAO) coatings on the fatigue life of 6061-T6 aluminum alloy in the rotating bending test. They found that the high-cycle fatigue life was significantly degraded due to the presence of MAO coatings, particularly when a low magnitude of stress and thicker coatings were used, while the surface roughness did not have a noticeable impact on the fatigue life. Alzoubi et al. [68] investigated the effects of coating thickness, materials, part geometry, temperature, and humidity on the fatigue life of thin-film metal coated flexible substrates, polyethylene terephthalate (PET), and polyethylene naphthalate 
(PEN) under high cycle bending loads. Ochi et al. [30] Yamamoto et al. [31] and investigated the impact of weld joints on the fatigue life of aluminum alloys.

- Residual stresses from coating process: Residual stresses induced by coating affect the fatigue life. Asquith et al. [69] indicated that the fatigue failure in hard oxidecoated aluminum was mitigated by interfacial compressive stresses while combining cold work with hard oxide coatings could improve fatigue performance. Under a thin film, thermal stresses were determined by the difference of thermal expansions of film and substrate. If a film was initially at a stress-free temperature T_0 and used at a different temperature $T$, the biaxial strain mismatch with respect to the substrate was evaluated as $\varepsilon=-\left(\alpha_{T, \text { film }}-\alpha_{T, \text { substrate }}\right)\left(T-T_{0}\right)$ [70], where $\alpha_{T, \text { film }}$ and $\alpha_{T, \text { substrate }}$ are the coefficients of thermal expansion of the film and substrate, respectively. This was supported by the work from Oskouei and Ibrahim [71]. Residual stresses in the surface coating affected material properties such as fatigue life, dimensional stability, and corrosion resistance. Shen et al. [72] proposed the use of micro-oxidation ceramic coatings for 6061 aluminum alloy to reduce the residual stresses induced during the coating process. They showed that the residual stress in the ceramic coatings was compressive in nature, and it increased at the beginning and then decreased with micro-arc oxidation. Sadeler et al. [73,74] investigated the impact of hard anodizing on the fretting fatigue behavior of a 2014-T6 aluminum alloy and found that the hardness was significantly improved up to about 380 (HV) from 175 after hard anodizing coating. Their results also indicated that fatigue life in a high stress region was shorter than that of the other material conditions, whereas the fatigue life in a low stress region was longer than that of the materials (T6 heat treated). Microscopic examination showed that fatigue fracture was initiated in the coating at high-stress regions, whereas fatigue fracture initiation started on the interface between the coating and substrate in low stress regions. Mindivan [75] tried WC-1Co+6\% ethylene (ETFE) coating on AA2024-T6 aluminum alloy with the process of plasma spray and high velocity oxygen fuel (HVOF); it was found that the HVOF substrate exhibited higher hardness, greater contact angles, better tribological performance, and a higher amount of retained WC when compared to the plasma sprayed WC-10Co+6\% ETFE coating. Tribological behavior of coatings at interface: The fatigue life of a coated aluminum alloy is also closely related to the tribological behavior at the contact interface. The research monograph [76] investigated the effect of surface coating on wear. In particular, the chapter by Ramalingam and Zheng [77] presented an analytic model on the stress distribution caused by the elastic difference of coating and substrates. Sheng [78] developed experimental techniques to assess the quality of thin polymer films, including friction, durability, and interfacial adhesion. The characteristics of friction and durability of PTFE films on aluminum substrate were investigated using ball-on-disk and ball-on-plate configurations. The effects of normal forces, sliding speed, and surface roughness on the friction coefficient were quantitatively examined by the variance. The results indicated that the native surface roughness of the substrate had the most significant effect on the coefficient of friction and durability, and accordingly, surface roughness of $0.5 \mathrm{~m}$ had the best durability of PTFE thin film.

- Operating temperature: Material strengths, including fatigue strength, vary with temperature. Bahaideen et al. [79] observed that the fatigue life of 2024-T4 aluminum alloy was reduced by a factor of 1.2 to 1.4 at an elevated temperature in comparison with that at room temperature. Brammer [80] used the traditional strain-life relation to characterize the fatigue behaviors of 6061-T6 and 7075-T651 aluminum alloys. The study found that the impact of heat exposure to low cycle fatigue was negligible; however, the high cycle fatigue was decreased significantly due to heat, and cracks were initialized as intermetallic particles in the peak-aged alloys and debonded particles. Oskouei and Ibrahim [71] studied Al 7075-T6 coated with $3 \mu \mathrm{m}$ thick titanium nitride (TiN) and found the deposition process operated at a higher temperature reduced the tensile properties of the coating-substrate system. 


\subsection{Contact Stresses and Fatigue Damage at Interfaces}

Fatigue lives of moving parts in actuators were determined by the contact stresses at the interfaces of coating and substrates. Hard anodizing produces a hard, wear- and abrasion-resistant coating of aluminum oxide on the surface of aluminum alloys. However, aluminum substrate is much more compliant than the coating, i.e., the Young's modulus of the hard coating is several times higher than the aluminum substrate. When the coated aluminum is loaded, differential displacements are generated in the substrate and the coating, and this leads to high stresses in the film and at the film-substrate interface. Film fracture and film-substrate debonding (spalling or flaking) can then occur and thus lead to severe wears.

Due to the reciprocating forces at contacts, the fatigue damage of a Teflon impregnated hard coated aluminum part was the combined effect of adhesion and surface fatigue wear, and the responsible wear modes are galling and spalling. Galling is caused by macroscopic transfer of material between metallic surfaces during transverse motion (sliding). Galling occurs frequently whenever metal surfaces are in contact, sliding against each other, especially with poor lubrication. Galling often occurs in high-load, low-speed applications but also occurs in high-speed applications with very little load. Spalling occurs at high stress contact points, for example, in a ball bearing. Figure 3 shows two microscope images of the failed anodized sample. Figure 3a shows the thickness of the Teflon impregnated anodized surface layer, and Figure $3 b, c$ shows the images of the failed anodized surfaces. In the direction of sliding motion, an adhesive wear pattern is observed in Figure 3b, and a flake-like damage pattern is observed in Figure 3c.

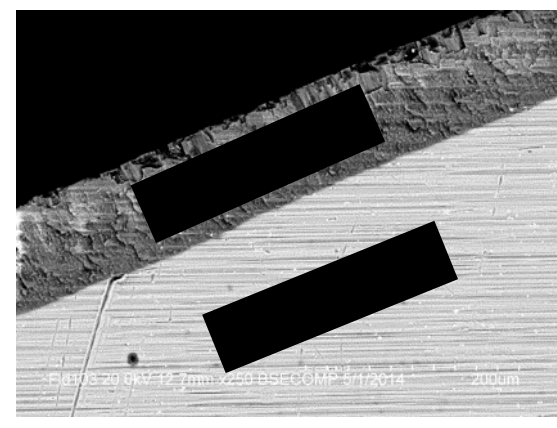

(a) Cross-section

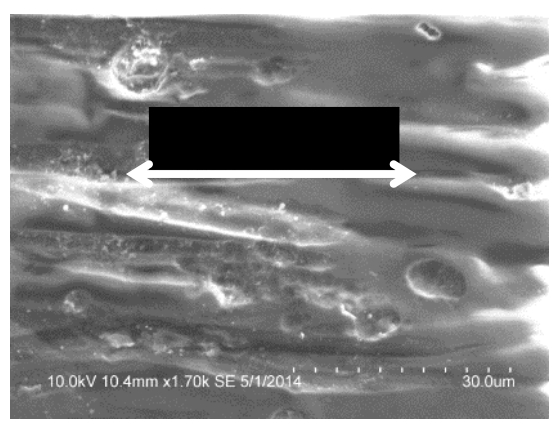

(b) Galling

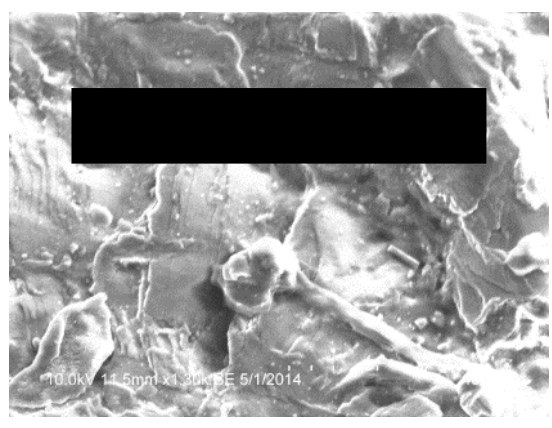

(c) Spalling

Figure 3. Scanning electron microscope images of failed anodized layers.

\section{Finite Element Modeling for Fatigue Analysis}

Finite element analysis (FEA) is a numerical technique for finding approximate solutions to boundary value problems for differential equations. FEA-based numerical methods have been widely used in stress analysis, failure analysis and diagnoses, and simulationbased optimization about coating systems [64]. It has been well accepted that FEA is the prevalent technique to analyze the physical phenomena in various engineering domains, such as solid mechanics, fluid mechanics, and thermal dynamics. FEA is also applied in gaining a better understanding of mechanical and chemical properties, manufacturing processes, and service behaviors of coated surfaces. The growth and characterization of multiplayer protective coatings have recently drawn a great deal of attention, while the design of these coatings still relies largely on experimental approaches. There has been some recent progress made to develop a method for the optimization of coating structure before physical deposition to save time and materials. Mackerle [81] gave a comprehensive review on the FEA applications in the design of simulation of coatings as well as material properties. There have been over 1000 papers during the last ten years, and the subjects span over surface modifications, coating simulations, and practical coating applications. 


\subsection{FEA-based Fatigue Analysis}

As introduced in Section 2, the three methods for determining the fatigue life of a material are the strain-life method, linear fracture mechanics method, and stress-life method. Based on the purpose of fatigue analysis and availability of fatigue material properties, different methods are to be applied. The first two methods are appropriate for applications with low loading cycles if a fatigue failure can be defined based on the size of the crack. Alzoubi et al. [68] considered the fatigue behavior of PTFE coated metals in a microelectronic device. Layered shell elements in the ANSYS software package were used to simulate the bending of coated thin-films to predict stress intensity and crack growth They found that the coatings can affect the fatigue life significantly. Wei and James [82] modeled the plasticity-induced crack closure behavior in various bi-material specimens. In particular, they analyzed the stress-level at the fatigue crack-opening and the crack-tip deformation fields (Modes I and II). In their models, a crack was assumed to open in an 'unzipping' fashion, and the crack-opening load was determined according to the separation of the fracture surface at the first node behind the crack-tip. Basescu et al. [83] investigated the contact fatigue of $40 \mathrm{Cr} 130$ coated metal under different lubrications, where coating was introduced to improve the wear resistance of cams. An FEA model was used to evaluate stress distributions, and the crack growth was associated with the fatigue life. Farley et al. [84] studied the fatigue behavior of a highly loaded coated surface with rolling and sliding contacts on a low loading cycle. The damage that occurred to the substrate was associated with the accumulation of plastic strains. Their fatigue model was based on the strain-life method.

The stress-life method seems appropriate at the preliminary conceptual design stage of products when: (1) a high loading cycle is desired in its application; (2) the mechanism of defining crack size of fatigue is unavailable; (3) there are limited data on fatigue material properties; (4) a large number of design variables need to be considered. It is critical to find the origins of concentrated stresses and minimize the levels of stress to improve fatigue life of coated parts [81]. The stress-life method is able to correlate stresses and characterized loads with the fatigue life. Lakkaraju et al. [85] developed an FEA model to predict the Hertzian contact stress in multilayer systems to find the optimal thicknesses of individual layers in a multilayer coating-substrate system that can reduce stresses and/or strains in the system.

\subsection{Fatigue Analysis in Product Designs}

Machine components in many applications are vulnerable to fatigue failures under dynamic loading. Dynamic loads can be mechanical, thermal, chemical loads, or combinations. FEA methods have been applied to investigate the stress distributions and deformations in singe, bilayers, and multilayers coating structures under different loading conditions, such as pressure, mixed normal, and tangential loads. However, most FEA models were developed for test specimens as validation tools for fatigue material properties. For example, Baragetti and Tordini [86] established an FEA model for the standardized hourglass-shaped specimen in its rotating test to determine the axial stress distribution over the critical cross-section. Yildiz et al. [87] developed a fretting fatigue model for their fretting lab setup. In their model, quadratic tetrahedron solid elements were used for the objects, CONTA174 and TARGE170 elements were used at the contact surfaces, and a face-to-face surface algorithm with asymmetric pairs was adopted to contact detection. Bouzakis et al. [88-90] developed a rolling contact fatigue test under elastic deformation on coatings and plastic deformation on substrates. A non-linear FEA model was established to understand the relationship between the stress distributions and fatigue life of a specimen under ball-on-rod rolling contact. Material properties of coatings were obtained from nano-hardness investigations, and the data with plastic deformation were obtained with the aid of an experimental-computational FEM-based procedure to create a reproducible simulation model, independent of the configuration and loading conditions of individual tests. In addition, Bouzaki et al. [90] studied the strain rate effects on coating surfaces. 
Between 80 and $85 \%$ of inserts of cutting tools are coated; therefore, the fatigue life of cutting tools under impact loads has been studied extensively. For example, Otieno et al. [91] discussed the dependence of the fatigue life of a cutting insert with temperature, heat transfer, cutting speed, and a minimal use of coolant. Metals and alloys are widely used in implant materials due to their superior material properties. One important factor in determining the service life is the fretting fatigue mechanism. Fretting is surface damage that occurs when the contacting surfaces experience an oscillatory motion with a small amplitude. Over $70 \%$ of the implant materials are damaged by fretting fatigue. In order to improve the fretting fatigue, different surface modifications, such as the plasma assisted thermochemical treatment, ion implantation, spray costing, and biocompatible think film deposition, have been used [87]. Liu [92] considered the multiplayer diamond-like carbon coated hip joints and found that high hardness coatings were able to resist plastic deformation to reduce the stress concentration and avoid failure of the coating. Kanber and Demirhan [93], assuming that elastic substrates are bonded with coatings and in contact with each other under normal and shear forces, investigated the fatigue behavior of a socket joint, ball on a flat plate, roller on a guide, and spur gear systems. Sridhar et al. [94] modeled a coated pistol to look into the thermal barrier by coating and studied the effects of design variables of such as material properties, coating thickness, residual stress, and different boundary conditions. Mituletu et al. [95] investigated the contact stresses that occurred in Xylan 1052 coated toothed wheels, where all the parts except for coatings were treated as rigid bodies to reduce the computations. The results showed that the stress distribution on the coating was extended to the surfaces of tooth flanks due to the lower strength of plastic materials in contrast to that of the steel base. Ringsberg et al. [96] proposed a method for fatigue design of coated rails. They incorporated the shakedown theory and field tests with an FEA model to predict the fatigue life. Efstathiou et al. [97] studied the fatigue behavior of coated extrusion dies, where the effects of extrusion processing, die geometry, and coating materials on the fatigue life were investigated.

\subsection{FEA Software Packages for Fatigue Analysis}

A large number of attempts have been made to solve indentation problems with FEA. A detailed bibliographical review on the studies from 1997 to 2000 can be found [81,98]. FEA software packages, such as Abaqus, Ansys, SolidWorks, Deform3D, AdvantEdge, Marc, Castem, Nastran, and Adina, can be used for the numerical simulation of fatigue analysis. Table 2 is a summary of the FEA packages used by researchers for the fatigue behavior of parts in various applications. Note that commercial solid modeling and finite element analysis are very similar, and the overlapped capabilities are over 90\% [99]. Some FEA packages support all of the three fatigue analysis methods. For example, Bishop et al. [100] introduced the capabilities of MSC software in fatigue analysis. The fatigue module in MSC uses the three fatigue life prediction methods: total life, crack initiation, and crack propagation.

Table 2. A summary of FEA packages, fatigue life methods, and applications.

\begin{tabular}{|c|c|c|c|}
\hline FEA Packages & References & Fatigue Methods/Others & Applications \\
\hline Ansys & $\begin{array}{c}\text { Peyraut et al. [98] } \\
\text { Yildiz et al. [87] } \\
\text { Carlson et al. [101] } \\
\text { Navarro et al. [102] } \\
\text { Alzoubi et al. [68] } \\
\text { Sangkla et al. [103] } \\
\text { Kolesnikov et al. [104] } \\
\text { Sliwa et al. [105,106] } \\
\text { Dobrzanski et al. [107] } \\
\text { Wu et al. [64] } \\
\text { Tasdemirci and Apalak [108] } \\
\text { Wei and James [82] } \\
\text { Sridhar et al. [94] } \\
\text { Basecu et al. [83] } \\
\text { Bouzaki et al. [88-90] } \\
\text { Kanber and Demirhan [93] } \\
\text { Majzoobi et al. [109] }\end{array}$ & $\begin{array}{c}\text { Stress-life method } \\
\text { Stress-life method } \\
\text { Strain-life method } \\
\text { Linear Fracture Mechanism } \\
\text { Linear Fracture Mechanism } \\
\text { Stress-life method } \\
\text { Stress-life method } \\
\text { Stress-life method } \\
\text { Stress-life method } \\
\text { Stress-life method } \\
\text { Stress-life method } \\
\text { Linear Fracture Mechanism } \\
\text { Temperature } \\
\text { Stress-life method } \\
\text { Strain-life method } \\
\text { Contact mechanics } \\
\text { Stress-life method }\end{array}$ & $\begin{array}{c}\text { Indentation test } \\
\text { Fretting fatigue test } \\
\text { Material properties } \\
\text { Fretting fatigue test } \\
\text { Bending test } \\
\text { Grippers } \\
\text { Rails } \\
\text { Coatings on steel } \\
\text { Coatings on steel } \\
\text { Ceramic coated steel } \\
\text { Indentation test } \\
\text { Composite materials } \\
\text { Piston } \\
\text { Wheel to wheel contact } \\
\text { Indentation test } \\
\text { Thin to medium coating } \\
\text { fasteners }\end{array}$ \\
\hline
\end{tabular}


Table 2. Cont.

\begin{tabular}{|c|c|c|c|}
\hline FEA Packages & References & Fatigue Methods/Others & Applications \\
\hline \multirow{11}{*}{ Abaqus } & Farley et al. [84] & Strain-life method & Rolling and sliding contact \\
\hline & Baregetti et al. [110] & Linear Fracture Mechanism & PVD coating \\
\hline & Baregetti [111] & Linear Fracture Mechanism & Coated spur gears \\
\hline & Baragetti and Tordini [86] & Strain-life method & Rotating fatigue test \\
\hline & Baragetti and Tordini [112] & Strain-life method & Spur gears \\
\hline & Basecu et al. [83] & Stress-life method & Wear at interface \\
\hline & Ma et al. [113] & Stress-life method & Coated carbide drill \\
\hline & Miao et al. [114] & Hardness analysis & Indentation test \\
\hline & Ronkainen et al. [115] & Stress-life method & Diamond-coated drills \\
\hline & Mount [116] & Linear Fracture Mechanism & Thin-film coating \\
\hline & Sheng [78] & Contact mechanics & Thin polymer films \\
\hline FEMLAB & Lakkaraju et al. [85] & Stress-life method & Indentation test \\
\hline \multirow{4}{*}{ Solid Works /Comos M } & Mituletu et al. [95] & Stress-life method & Toothed wheel \\
\hline & Madalina et al. [117] & Stress-life method & Piston head \\
\hline & Sroub et al. [118] & Stress-life method & Thermal behaviors of coats \\
\hline & Liu [92] & Stress-life method & Metal-on-metal joint replacements \\
\hline Unspecified Codes & McCook et al. [42] & $\begin{array}{l}\text { Strain-life method and stress-life } \\
\text { methods }\end{array}$ & Pin-on-disk test \\
\hline \multirow{2}{*}{ COMSOL } & Borri et al. [119] & Stress-life method & Thermal behavior \\
\hline & Liu [92] & Stress-life method & Hip joint \\
\hline PAFEC & Hand et al. [120] & Stress-life method & Window's protective coating \\
\hline MSC/Nastran & Rahman et al. [121] & Stress-life method & Cylinder block \\
\hline Deform3D & Efstathiou et al. [97] & Stress-life method & Extruded dies \\
\hline GENSYS & Ringsberg et al. [96] & Linear Fracture Mechanism & Rails \\
\hline AdvantagEdge & Otieno et al. [91] & others & Cutting Inserts \\
\hline \multirow{11}{*}{ Custom Codes } & Polonsky and Keer [122] & Linear Fracture Mechanism & Multilayer coatings \\
\hline & Nilsson [123] & Analytical models & Wear \\
\hline & Park et al. [124] & Strain-life method & Coated cutting tools \\
\hline & Zhong et al. [70] & Strain-life method & Glass-modeling dies \\
\hline & Choi and Liu [125] & Crack life model & CBN coated tools \\
\hline & Mesbahi et al. [38] & Adaptive neuro-fuzzy inference & Composite materials \\
\hline & Avanzini et al. [46] & Strain-life method & Composite materials \\
\hline & Navarro et al. [102] & Linear fracture mechanics & Coated aluminum alloys \\
\hline & Ribeiro et al. [126] & Linear fracture mechanics & Welds \\
\hline & Guler et al. [127] & Fracture mechanism & Graded coating \\
\hline & Gan et al. [43] & Fracture mechanism & Composite materials \\
\hline
\end{tabular}

\section{Challenges in Virtual Fatigue Analysis}

Numerous studies have been published on the virtual fatigue analysis of machine components, including coated components. The majority of these studies have been conducted as a means to validate material properties under test conditions or as a qualitative study on the relations of material properties of substrates to the coating designs and processes. A relatively small number of studies have been found on the virtual fatigue analysis for actual product designs, such as welds, spur gears, and hip joints. It seems feasible to analyze fatigue of coated parts virtually and utilize the predicted fatigue results for the optimization of new grippers. However, some technical challenges have been identified based on the present literature review. These are discussed in this section.

\subsection{Modeling of Thin Coating}

The ratio of coating thickness to other geometric dimensions is in microns. The coating thickness of the parts in the gripper is in the range of 0.0017 to 0.0023 in. Due to a mismatch between the coating thickness and other geometric dimensions of the part, there are technical difficulties in modeling a thin coating layer in FEA; namely, the elements for the coating layer can be greatly distorted in the meshing process. The first solution introduced in the literature $[70,116,118]$ is to use shell elements for the coating layer. As the shell el- 
ement considers dimensions in only two directions, it is appropriate for an object with a mismatching size in the third direction. However, our preliminary study has shown that it is not feasible to model the parts in the gripper by using the shell element. The main reason is that penetration constraints between both the top and bottom surfaces of the layer and surfaces of other parts in contact cannot be defined. Note that the penetration constraints of the shell element cannot solely be applied to its neutral surface as this violates the contact conditions of the coat layer in the actual part. The second solution is either to employ a two-dimensional model instead of three-dimensional or to model a small region of the most interest with fine meshes. This will allow the modeling of the coating locally. However, this requires additional work to define the load on the region based on the external loads and constraints globally [103].

\subsection{Fatigue Properties of Coating}

To obtain reliable results from the virtual fatigue analysis, information about material properties of both substrates and coating must be available. In the present work, the substrates are well-known aluminum alloys, 6061-T6 and 6063-T6, and the material properties of these alloys can be found from various sources. However, very limited information is available on the material properties of the coating. Although some relevant data of coated aluminum alloys are available [128-131], direct applications of existing properties should be practiced with caution because material properties of coating depend on the coating process and the constitution of coating materials. In case the coating is required to be treated separately in the finite element model, a subroutine algorithm to reference the material properties that includes the S-N curve must be available.

\subsection{Fluctuating Loads and Boundary Conditions}

Finite element modeling depends on the characterization of dynamic loads and boundary conditions. For an actuator, these conditions can be varied significantly from one application to another. In addition, some level of idealization is to be made when external loads and boundary conditions are defined in FEA modeling. For example, some of the common questions to be answered in developing an FE model for a virtual fatigue analysis are:

- Whether a pressure or force load should be applied?

- How to apply a moment load adequately?

- How to define contact and component sets for the assembled gripper appropriately?

- How to model the friction at contact interfaces?

- What set of surfaces should be constrained and in what form?

- What is an appropriate ratio of the mean and alternating loads in the characterization of loads?

- Is it necessary to take into account the non-linearity of material properties?

\subsection{Robustness of Solving Process}

It is unrealistic to develop an analysis process and automate the virtual fatigue analysis iterations. Manual interventions are required from time to time to deal with the issues during the procedures of meshing, modeling, solving, and post-processing. For example, it is very common for an FEA package to produce warning messages in the meshing process on distorted elements, compatibility at contact, or a large number of mismatching elements. Moreover, in the solution process, it is not uncommon that the solver does not converge to a solution with required accuracy within a limit of iterations. Therefore, designers should be able to change relevant settings in the package to obtain an acceptable result. It is not an easy task to specify the default settings for numerous parameters in the virtual fatigue analysis process to minimize manual interventions for similar products.

\subsection{Verification and Validation}

Before actually being used to replace a physical fatigue test, the effectiveness of the proposed method must be verified and validated. To the authors' knowledge, no benchmark 
work that can be used to verify the proposed FEA-based fatigue analysis method exists. Experiments or tests for verification of numerical results should be carefully planned, and a minimal set of material properties must be obtained so that the proposed process can be properly validated.

\section{Procedure for Systematic Virtual Fatigue Analysis}

Assume that the material properties of the coated aluminum alloy parts of the actuator are characterized and known. The bonding between the coating and substrate is still quite complicated, and a great deal of uncertainties are presented in defining the material properties of the coating, substrate, and their interface. Therefore, we propose to define the overall equivalent material properties of the coated materials; this would eliminate the difficulties of modeling the thin coat layer of coated parts. In using numerical simulation for fatigue analysis, moving parts are considered as homogeneous objects with given isotropic material properties. The following procedure is proposed to conduct a fatigue analysis of a moving part in the actuator. Note that SolidWorks Simulation is used as an example tool for the graphic illustrations below.

\subsection{Simplify Assembly Models}

The contact surfaces on two or three coated parts are of most concern. It is critical to simplify the assembly model of the actuator (see Figures 4 and 5 as an example). The less relevant parts and features are suppressed to make the fatigue analysis tangible.

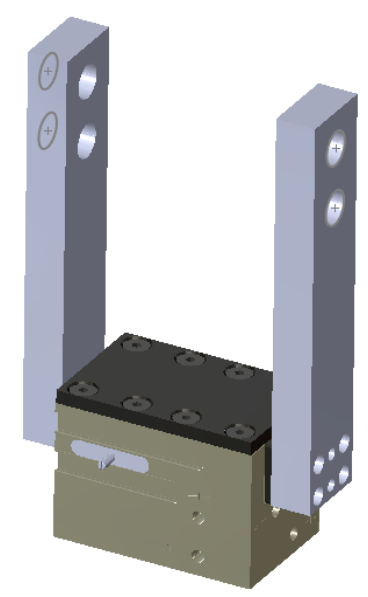

Figure 4. Detailed assembly model of an actuator.

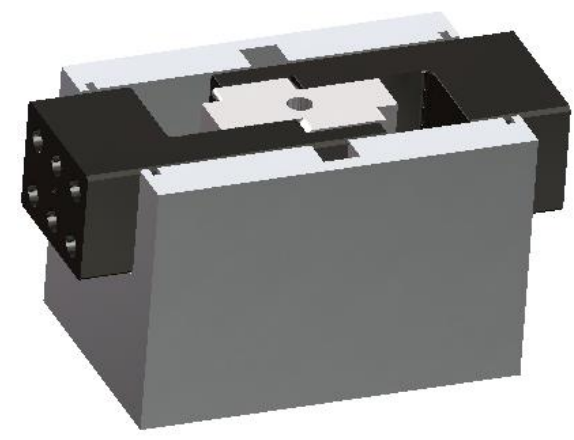

Figure 5. Simplified model with movable parts and contacts.

\subsection{Define Material Properties of Coated Parts}

Multiple materials are used in the actuator; hence, a custom material library should be established to include the properties of these materials. In particular, the properties of coated aluminum alloys must be defined (see example in Figure 6). 


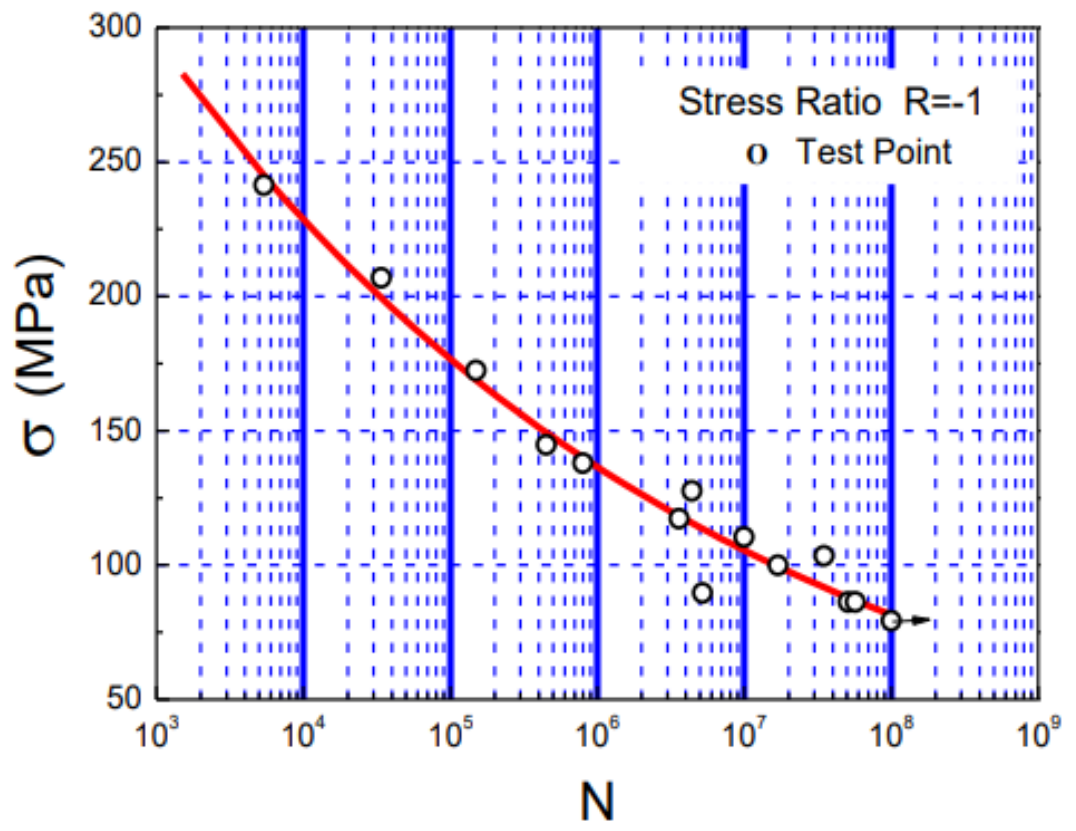

Figure 6. S-N curve of coated 6061-T6 [128-131].

\subsection{Contacts with Motion}

The contact conditions at the interfaces of parts influence the stress distribution greatly. For a machine element, a relative motion will be allowed along a certain direction. Therefore, it is appropriate to define the contact type as a 'virtual wall' with a relative tangent motion. This contact type allows for choosing 'rigid' or 'flexible' properties for the motion on the target plane and specifying the coefficient of friction at the interface.

\subsection{Constraint Types at Contact Surfaces}

An FEA model cannot be solved unless the defined constraints are sufficient to remove all possible rigid body motions. The assembly model of the actuator has fixed constraints on its root part only, and the rigid body motions of other parts must be constrained by their bonding relations at contact surfaces. Geometric constraints at a fixed contact include 'no penetration', 'bonded', 'shrink fit', and 'allow penetration', and an appropriate constraint type must be specified for contact surfaces. Note that most simulation software specifies 'bonded' as the default contact type.

\subsection{External Loads}

The load of picking and placing operations by tools is transferred to the tensile and moment loads on the jaws (see Figures 7 and 8). They should be defined accordingly to calculate the stress distributions on jaws and jaw drivers.

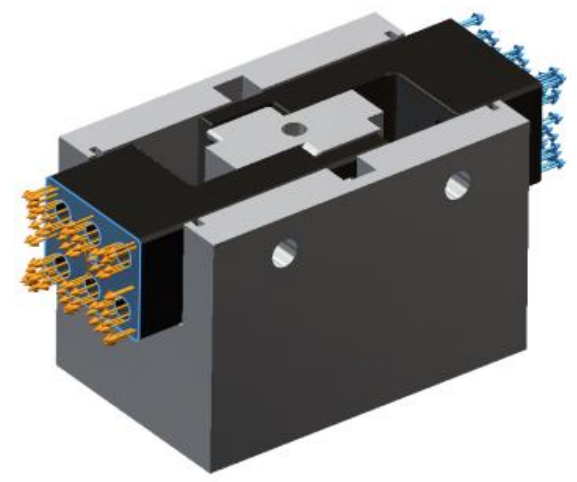

Figure 7. Axial loads. 


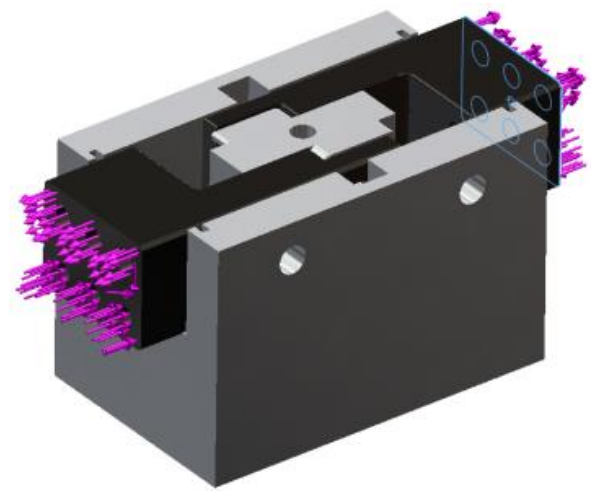

Figure 8. Torque over movable parts.

\subsection{Meshing of Part Geometries}

The accuracy of FEA depends greatly on the quality of meshes. Mesh control (see Figure 9) is desirable so that fine meshes can be generated locally over critical contact surfaces (see Figure 10).

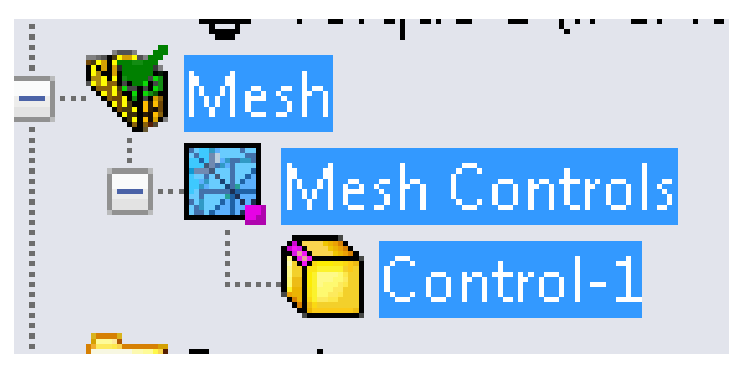

Figure 9. Mesh control over critical contact surfaces.

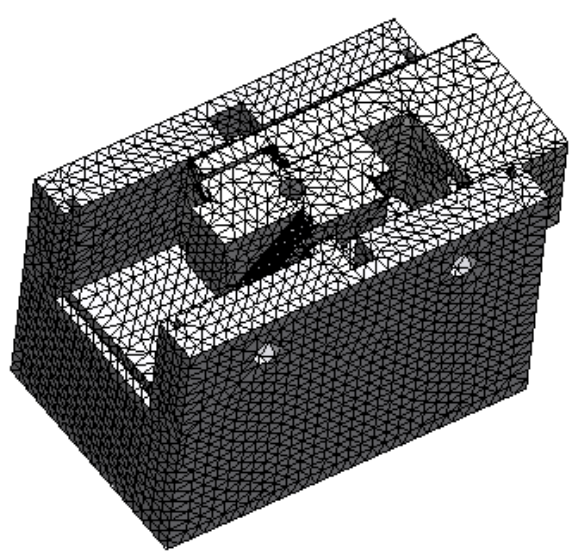

Figure 10. Meshing from mesh controls.

\subsection{Solving FEA Models}

It is very rare that an FEA model can be solved smoothly without errors and problems on the first try. Solving an FEA model is actually an iterative procedure to refine all the definitions in previous steps so that it eventually leads to a final solution (see Figures 11 and 12). 


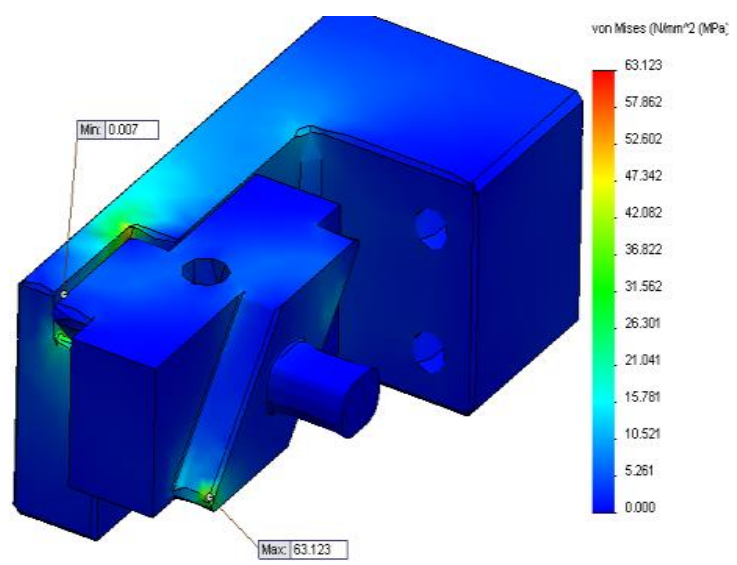

Figure 11. Stress distribution on jaw drive.

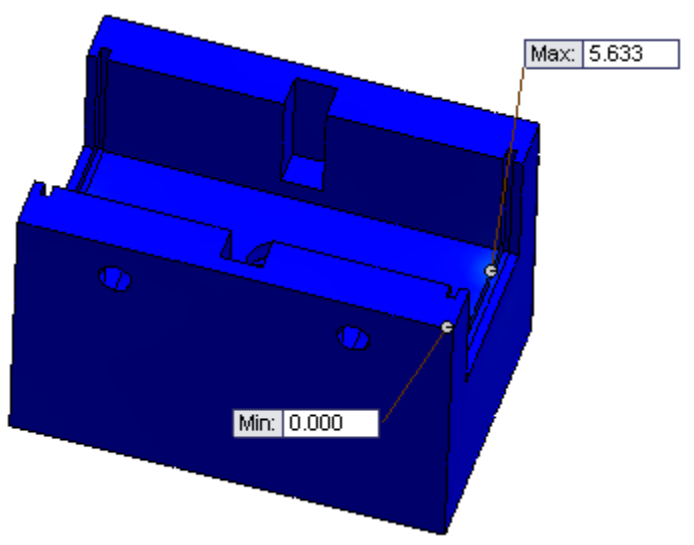

Figure 12. Max/min stress on base.

\subsection{Fatigue Analysis Model}

A fatigue analysis model will be defined using the results from the static analysis (see Figure 13). Loading conditions are to be defined, and the S-N curves of all materials are needed to determine the fatigue life (see Figure 14).

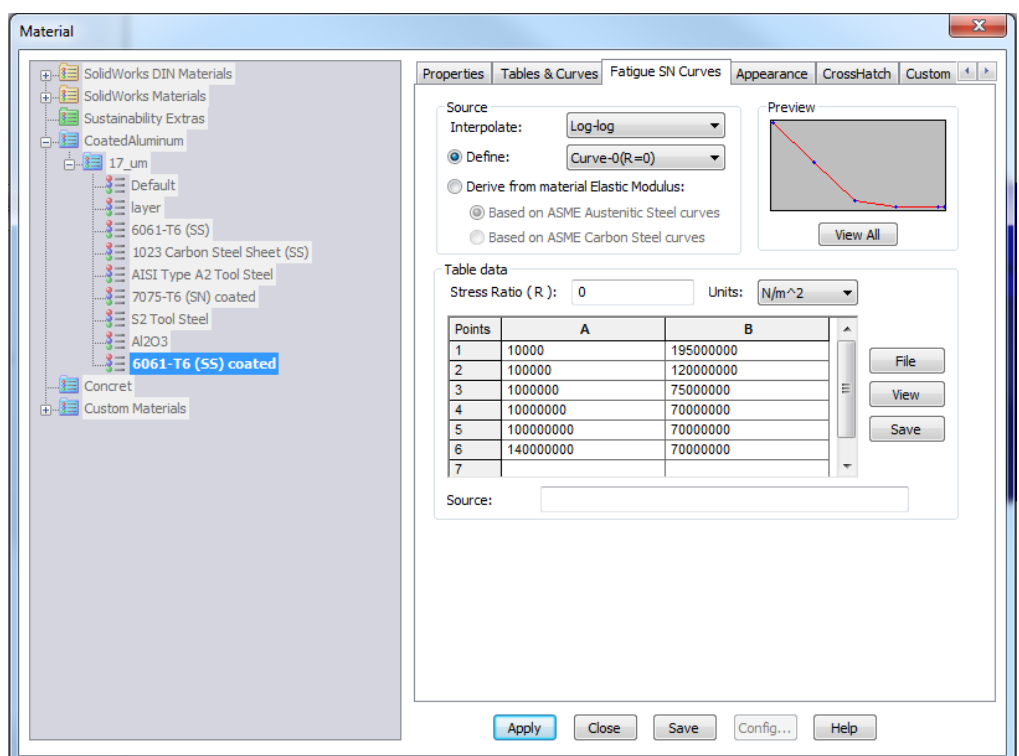

Figure 13. Definition of S-N curves. 


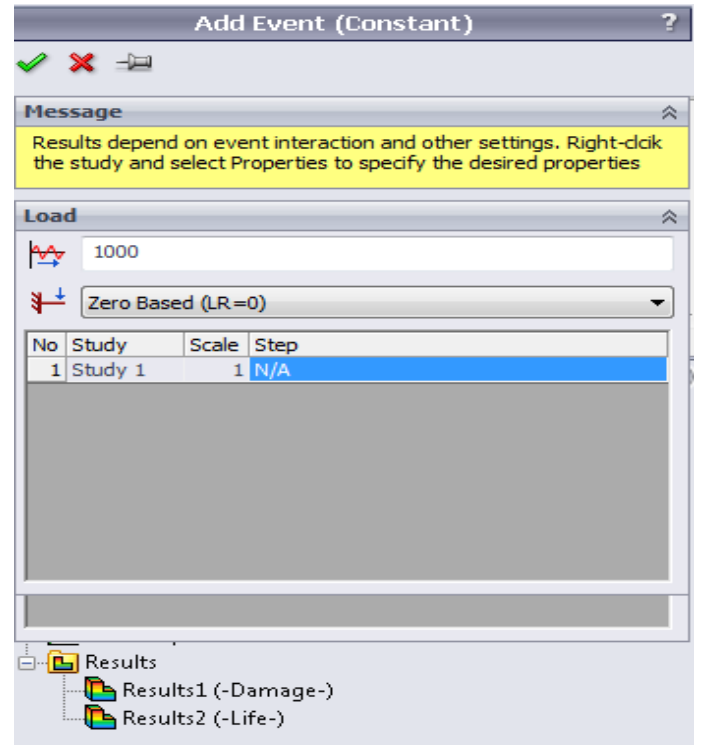

Figure 14. Definition of fluctuating loads.

\subsection{Assess Fatigue Life}

If the maximum stress in a part is below its endurance limit, the part is free of fatigue failure. Otherwise, the fatigue life and the damage on the part can be predicted based on the fatigue analysis under the given loading conditions (see Figures 15 and 16).

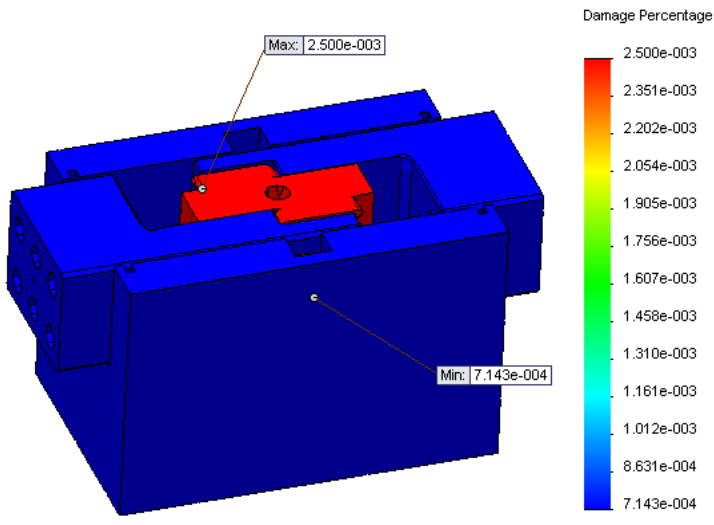

Figure 15. Prediction of damage.

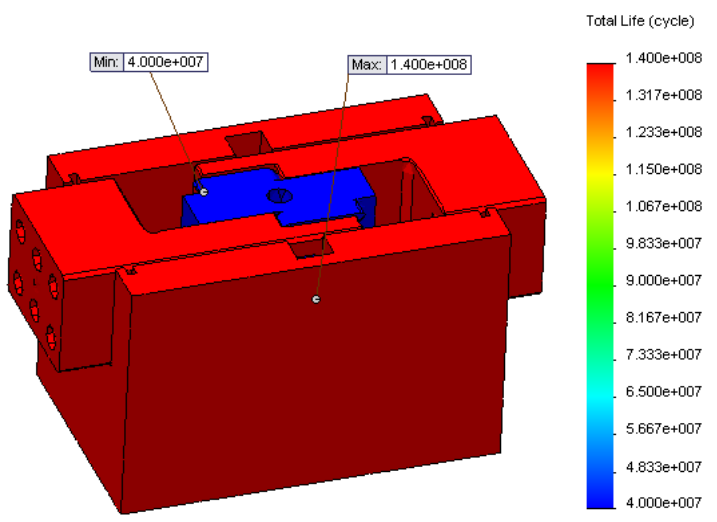

Figure 16. Predicted fatigue life in cycles. 


\section{Summary}

This paper has discussed the studies on modeling and analysis of contact stress and fatigue life of moving parts to: (1) explore the feasibility of using a numerical simulation tool to predict the fatigue life of an actuator; (2) identify the challenges of fatigue analysis for moving parts with thin-layered hard coatings, mixed contact interfaces, and fatigue analysis under fluctuating loads; (3) propose a practical method with which the fatigue life of an actuator can be predicted with an acceptable level of accuracy. The outcomes of this study are summarized as below:

(1). There are three methods to predict fatigue life of machine parts, i.e., strain-life method, linear elastic fracture method (LEFM), and stress-life method. The stress-life method is most commonly used, in particular, for high-cycle applications and applications beyond the endurance limit. The other two methods require simulating the accumulation of cracks or stains, which is not practical in fatigue analysis of actuators.

(2). Teflon Impregnated and hard coated surfaces have been widely used to improve the wear and corrosion resistance of aluminum alloys. However, it is found that hard coated surfaces adversely affect the fatigue life of substrates. Efforts have been made on the processes and methods to alleviate this effect, but a general solution to eliminate this effect is not available.

(3). Many FEA tools, such as Ansys, Abaqus, SolidWorks, FEMLab, Deform3D, Nastran, COMSOL, and some other sophisticated FEA codes, have capabilities for fatigue analysis of coated parts. However, most FEA models are limited to two-dimensional applications and they are mainly for verification purposes under testing conditions. Few three-dimensional FEA models are currently available for the fatigue life analysis of hard coated parts. Detailed modeling of assembled parts with thin coatings poses challenges to any FEA package because an FE model would require a prohibitively large number of elements for a convergent solution.

(4). In comparison to traditional engineering materials, the knowledge of material properties of hard-coated aluminum alloys is very limited. Due to the importance of material properties in numerical simulations, experiments are required to characterize the material properties of the hard coat itself and the bonding mechanism of the hard coat and substrate interface. Note that the variables and parameters in anodizing processes could affect the material properties of the hard coated aluminum alloy, and thus it is important to maintain consistency in material properties in design/analysis, prototyping, testing, and verification.

(5). Developing a design process to predict the fatigue life of a hard coated part is feasible. The activities involved in the design process include: (a) preparation of a CAD model, (b) defining, revising, and expanding custom material library, (c) defining fatigue properties such as S-N curves, (d) building and running an FEA model for static analysis, (e) extending the static analysis model to fatigue analysis, and (f) supporting the parametric design for new product development. During the design process, manual intervention and arbitration should be minimized.

Author Contributions: Conceptualization, Z.B., B.K., P.O.; literature reviews, organization, and writing, Z.B., B.K.; illustrative case development, Z.B.; writing, organization, editing, Z.B., P.O.; proofreading, Z.B., B.K. All authors have read and agreed to the published version of the manuscript.

Funding: This research received no external funding.

Institutional Review Board Statement: Not applicable.

Informed Consent Statement: Not applicable.

Data Availability Statement: The presented work is a literature survey, and there is no research data other than the findings included in the conclusion section. Please feel free to contact the corresponding author if readers would like to learn more about the sources of references.

Conflicts of Interest: The authors declare no conflict of interest. 


\section{References}

1. Bi, Z.M.; Wang, X.Q. Computer Aided Design and Manufacturing; Wiley: Hoboken, NJ, USA, 2020; ISBN 978-1-119-53424-2.

2. Bi, Z.M.; Meruva, K. Modeling and predication of fatigue life of robotic components in intelligent manufacturing. J. Intell. Manuf. 2019, 30, 2575-2585. [CrossRef]

3. Liu, C.; Bi, Z.M.; Ran, J.; Gu, J.; Wang, X.; Zhang, C. Modeling and Verification of Fatigue Damage for Compliant Mechanisms. Robotica 2019, 37, 1-17. [CrossRef]

4. Bi, Z.M.; Mueller, D. Finite element analysis for diagnosis of fatigue failure of composite materials in product development. Int. J. Adv. Manuf. Technol. 2016, 87, 2245-2257. [CrossRef]

5. Bi, Z.M.; Mueller, D. Friction Predication on Pin-to-Plate Interface of PTFE Material and Steel. Friction 2019, 7, 268-281. [CrossRef]

6. Nie, S.; Li, Y.; Shuai, G.; Tao, S.; Xi, F. Modelling and simulation for fatigue life analysis of robots with flexible joints under percussive impact forces. Robot. Comput. Integr. Manuf. 2016, 37, 293-301. [CrossRef]

7. Xu, D.; Wei, Q.; Qu, S. Fatigue life analysis of the actuator based on co-simulation. In Proceedings of the 2015 First International Conference on Reliability Systems Engineering (ICRSE), Beijing, China, 21-23 October 2015. [CrossRef]

8. Kingsley, D.A.; Quinn, R.D. Fatigue life and frequency response of braided pneumatic actuators. In Proceedings of the IEEE Robotics and Automation Conference, Washington, DC, USA, 11-15 May 2002.

9. Woo, S.C.; Goo, N.S. Effect of electric cyclic loading on fatigue cracking of a bending piezoelectric hybrid composite actuator. Compos. Sci. Technol. 2009, 69, 1764-1771. [CrossRef]

10. Zhang, W.J.; Luttervelt van, C.A. Towards a resilient manufacturing system. CIRP Ann. 2011, 60, 469-472. [CrossRef]

11. Kang, J.J.; Xu, B.S.; Wang, H.D.; Wang, C.B. Investigation of a novel rolling contact fatigue/wear competitive life test machine faced to surface coating. Tribol. Int. 2013, 66, 249-258. [CrossRef]

12. Seo, J.W.; Jun, H.K.; Kwon, S.J.; Lee, D.H. Rolling contact fatigue and wear of two different rail steels under rolling-sliding contact. Int. J. Fatigue 2016, 83, 184-194. [CrossRef]

13. Lv, Z.Y.; Xiong, J.J.; Tong, L.; Zhu, Y.T. A practical approach for evaluating safe fatigue life of hydraulic actuator in helicopter based on a nominal force concept and minimal datasets. Aerosp. Sci. Technol. 2017, 62, 158-164. [CrossRef]

14. Garcia, M.A.; Veloso, L.A.M.; de Castro, F.C.; Arujo, A.; Ferreira, J.L.A.; da Silva, C.R.M. Experimental device for fretting fatigue tests in 6201 aluminum alloy wires from overhead conductors. Wear 2020, 460-461, 203448. [CrossRef]

15. Shabani, P.; Tageri-Begrooz, F.; Mousavi, S.S.S.; Shokrieh, M.M. Very high cycle and gigacycle fatigue of fiber-reinforced composites: A review on experimental approaches and fatigue damage mechanisms. Prog. Mater. Sci. 2021, in press. [CrossRef]

16. Sunde, S.L.; Haugen, B.; Berto, F. Experimental and numerical fretting fatigue using a new test fixture. Int. J. Fatigue 2021, 143, 1006011. [CrossRef]

17. Pilkey, W.D.; Pilkey, D.F.; Bi, Z.M. Peterson's Stress Concentration Factors; 4th Version; Wiley: Hoboken, NJ, USA, 2020; ISBN1 978-119532514. ISBN2 119532515.

18. Ramachandran, V.; Raghuram, A.C.; Krishnan, R.V.; Bhaumik, S.K. Failure Analysis of Engineering Structures: Methodology and Case Histories. 2005. Available online: http://nusretmeydanlik.trakya.edu.tr/MLZM\%20MKN/Failure_Analysis_of_ Engineering_Structures_Methodology_and_Case_Histories.pdf (accessed on 15 April 2021).

19. Nanninga, N.E. High Cycle Fatigue of AA6082 and AA6063 Aluminum Extrusions. Ph.D. Thesis, Michigan Technological University, Houghton, MI, USA, 2008. Available online: http://digitalcommons.mtu.edu/etds/18 (accessed on 15 April 2021).

20. Budynas, R.G.; Nisbett, J.K. Shigley's Mechanical Engineering Design; 10th Version; McGraw-Hill Connect Engineering: New York, NY, USA, 2014; ISBN 978-0-07-339820-4.

21. SAE. J1099, SAE Standards: Technical Report on Low Cycle Fatigue Properties Ferrous and Non-Ferrous of Materials. 2014. Available online: http://standards.sae.org/j1099_197502/ (accessed on 15 April 2021).

22. Pommier, S. Basics Elements on Linear Elastic Fracture Mechanics and Crack Growth Modeling. Doctoral. France. 2017. Available online: https:/ / hal.archives-ouvertes.fr/cel-01636731/document (accessed on 15 April 2021).

23. NASA/FLAGRO. Fatigue User's Guide>Crack Growth>NASA/FLAGRO. 2014. Available online: http://www.mscsoftware. com/training_videos/patran/Reverb_help/index.html\#page/Fatigue\%20Users\%20Guide/fat_growth.08.8.html (accessed on 15 April 2021).

24. Unigovski, Y.B.; Grinberg, A.; gerafi, E.; Gutman, E.M.; Moisa, S. Low-cycle fatigue of an aluminum alloy plated with multi-layer deposits. J. Optoelectron. Adv. Mater. 2013, 15, 863-868.

25. Aparcio, C. What is Fatigue Analysis? 2013. Available online: http://simulatemore.mscsoftware.com/what-is-fatigue-analysismsc-nastran/ (accessed on 15 April 2021).

26. Balzers Oerlikon. Coated Components: Greater Performance and Reliability; Balzers Oerlikon: Balzers, Liechtenstein, 2010.

27. Carroll, J.W. The Effects of Novel Surface Treatments on the Wear and Fatigue Properties of Steel and Chilled Cast Iron. Ph.D. Thesis, University of Michigan, Ann Arbor, MI, USA, 2012.

28. Cobden, R.; Bandury, A. Aluminum: Physical Properties, Characteristics and Alloys. Available online: https://www.yumpu. com/en/document/read/3968974/aluminium-physical-properties-characteristics-core-materials (accessed on 15 April 2021).

29. Borrego, L.P.; Abreu, L.M.; Costa, J.M.; Ferreira, J.M. Analysis of low cycle fatigue in AlMgSi aluminum alloys. Eng. Fail. Anal. 2004, 11, 715-725. [CrossRef] 
30. Ochi, H.; Sawai, T.; Yamanoto, Y.; Ogawa, K. Evaluation of tensile strength and fatigue strength of 6061 aluminum alloy friction welded joints by heat input and burn-off length. In Proceedings of the Twelfth International Offshore and Polar Engineering Conference, Kitakyushu, Japan, 26-31 May 2002.

31. Yamamoto, Y.; Ochi, H.; Sawai, T.; Yamaguchi, H.; Ogawa, K. Fatigue strength of friction-welded 6061 aluminum alloy joints. Mater. Trans. 2007, 48, 2909-2913. [CrossRef]

32. Alcoa. Alloy 6063: Understanding Extruded Aluminum Alloys. 2014. Available online: http://www2.galcit.caltech.edu/tongc/ $\mathrm{html} /$ data/elastic/Extruded_Alloy_6063.pdf (accessed on 15 April 2021).

33. MatWeb. Aluminum 6063-T6. 2014. Available online: http://weilandslidingdoors.com/wp-content/uploads/2012/05/weilandalu6063-properties.pdf (accessed on 15 April 2021).

34. Yahr, G.T. Fatigue Design Curves for 6061-T6 Aluminum; CONF-930702-14; Oak Ridge National Laboratory: Oak Ridge, TN, USA, 1993.

35. FEP Handbook. 2014. Available online: http:/ /www.rjchase.com/fep_handbook.pdf (accessed on 15 April 2021).

36. Dupont. An Introduction to DuPont Fluoropolymers, Part of DuPont Chemicals \& Fluoroproducts. 2014. Available online: http: //www2.dupont.com/GenX/en_US/assets/downloads/Dupont_Fluoropolymers_Introduction.pdf (accessed on 15 April 2021).

37. Dupont. Teflon PTFE Properties Handbook. 2014. Available online: http://www.rjchase.com/ptfe_handbook.pdf (accessed on 15 April 2021).

38. Mesbahi, A.H.; Semnani, D.; Khorasani, S.N. Performance prediction of a specific wear rate in epoxy nano-composites with various composition content of polytetrafluoroethylene (PTFE), graphite, short carbon fibers (CF) and nano-TiO2 using adaptive neuro-fuzzy inference system (ANFIS). Compos. Part B 2010, 43, 549-558. [CrossRef]

39. Gong, R.; Wan, X.; Zhang, X. Tribological properties and failure analysis of PTFE composites used for seals in the transmission unit. J. Wuhan Univ. Technol. Mater. Sci. Ed. 2013, 28, 26-31. [CrossRef]

40. Akdogan, G.; Stolarski, T.A.; Tobe, S. Wear of metal/PTFE coatings in rolling line contact. J. Mater. Sci. 2002, 37, 5013-5019. [CrossRef]

41. Akdogan, G.; Stolarski, T.A.; Tobe, S. Wear performance of polytetrafluoroethylene-metal coatings in rolling/sliding line contact. Proc. Inst. Mech. Eng. Part J J. Eng. Tribol. 2003, 217, 103-114. [CrossRef]

42. McCook, N.L.; Burris, D.L.; Kim, N.H.; Sawyer, W.G. Cumulative damage modeling of solid lubricant coatings that experience wear and interfacial fatigue. Wear 2007, 262, 1490-1495. [CrossRef]

43. Gan, Y.X.; Aglan, H.; Fauhnan, P.; Bryan, C. Fatigue fracture mechanisms of particle and fiber filled PTFE composites. J. Reinf. Plast. Compos. 2001, 20, 766. [CrossRef]

44. Aderikha, V.N.; Shapovalov, V.A. Effect of filler surface properties on structure, mechanical and tribological behavior of PTFEcarbon black composites. Wear 2010, 268, 1455-1464. [CrossRef]

45. Teku. PTFE_Fluoroplastic Properties and Characteristic Data. 2014. Available online: http://teku-gmbh.de/pdf_en/EN_ Fluoroplastics_s.pdf (accessed on 15 April 2021).

46. Avanzini, A.; Donzella, G.; Gallina, D.; Pandini, S.; Petrogalli, C. Fatigue behavior and cyclic damage of peek short fiber reinforced composites. Compos. Part B Eng. 2013, 45, 397-406. [CrossRef]

47. Frick, A.; Sich, D.; Heinrich, G.; Stern, C.; Gossi, M.; Tervoort, T.A. Relationship between structure and mechanical properties of melt processable PTFE: Influence of molecular weight and comonomer content. Macromol. Mater. Eng. 2013, 298, 954-966. [CrossRef]

48. Teoh, S.H. Fatigue of biomaterials: A review. Int. J. Fatigue 2000, 22, 825-837. [CrossRef]

49. Wang, Y.; Wang, H.; Yan, F. Investigation of transfer film of PTFE/bronze composites on 2024Al surface. Surf. Interface Anal. 2009, 41, 753-758. [CrossRef]

50. Gillig, F.G. Study of Hard Coating for Aluminum Alloys; WADC Technical Report; Cornell Aeronautical Laboratory, Inc.: WrightPatterson AFB, OH, USA, 1953; pp. 53-151.

51. ASM International. ASM Handbook Corrosion, 9th ed.; ASM International: Materials Park, OH, USA, 1998 ; Volume 13.

52. Shahzad, M.; Chaussumier, M.; Chieragatti, R.; Mabru, C.; Aria, F.R. Influence of surface treatments on fatigue life of Ai 7010 alloy. J. Mater. Process. Technol. 2010, 210, 1821-1826. [CrossRef]

53. Puchi-Cabrera, E.S.; Staia, M.H.; Santana, Y.Y.; Mora-Zorrilla, E.J.; Lesage, J.; Chicot, D.; Barbera-Sosa, J.G.; La Ochoa-Perez, E.; Villalobos-Gutierrez, C.J. Fatigue behavior of AA7075-T6 aluminum alloy coated with a WC-10Co-4Cr cermet by HVOF thermal spray. Surf. Coat. Technol. 2013, 220, 122-130. [CrossRef]

54. Ziemian, C.W.; Sharma, M.M.; Bouffard, B.D.; Nissley, T.; Eden, T.J. Effect of substrate surface roughening and cold spray coating on the fatigue life of AA2024 specimens. Mater. Des. 2014, 54, 212-221. [CrossRef]

55. Wanstrand, P. Wear Resistant Low Friction Coatings for Machine Elements: Possibilities and Limitations. Ph.D. Thesis, ACTA Universitatis Upsaliensis, Uppsala, Sweden, 2000.

56. Emeric, D.A.; Levine, S.; Washburn, K.L. The Effect of Surface Coatings on The Fatigue Strength of Aluminum Alloys; Report No. 2339; U.S. Army Mobility Equipment Research and Development Command: Fort Belvoir, VA, USA, 1981.

57. Goetz, J.M. Investigation of Coating Cracking and Fatigue Strength of 7050-T74 Aluminum Alloy with Different Anodize Coating Thicknesses. Available online: https:/ / kb.osu.edu/bitstream/handle/1811/327/Goetz_Thesis_SP05.pdf?sequence=1\& isAllowed=y (accessed on 15 April 2021). 
58. Pineiro-Jimenz, A.; Villalobos-Gutierrez, C.; Staia, M.H.; Puchi-Cabrera, E.S. Tensile and fatigue properties of 6063-T6 aluminum alloy coated with electroless Ni-P deposit. Mater. Sci. Technol. 2007, 23, 253-260. [CrossRef]

59. Murakami, R.-I. Fatigue Properties of Aluminum Alloy (A6061-T6) with Ultrasonic Nano-Crystal Surface Modification, Advanced Material Lab in Kyungpook National University. 2014. Available online: http:/ / www.me.tokushima-u.ac.jp/zairyoukyoudo/M2 2/No4\%20Fatigue\%20properties.pdf (accessed on 15 April 2021).

60. Puchi-Cabrera, E.S.; Maccio, R.; Staia, M.H. Fatigue behaviour of 7075-T6 aluminum alloy coated with WC-12Co alloy deposited by plasma spray. Surf. Eng. 2006, 22, 253-262. [CrossRef]

61. Baragetti, S.; La Vecchia, G.M.; Terranova, A. Variables affecting the fatigue resistance of PVD-coated components. Int. J. Fatigue 2005, 27, 1541-1550. [CrossRef]

62. Baragetti, S.; Lusvarghi, L.; Bolelli, G.; Tordini, F. Fatigue behavior of 2011-T6 aluminum alloy coated with PVD WC/C, PA-CVD DLC and PE-CVD SiOx coatings. Surf. Coat. Technol. 2009, 203, 3078-3087. [CrossRef]

63. Genel, K. Environmental effect on the fatigue performance of bare and oxide coated 7075-T6 alloy. Eng. Fail. Anal. 2013, 32, 248-260. [CrossRef]

64. Wu, Z.-Q.; Xia, Y.; Li, G.; Xu, F.-T. Finite element analysis on stresses field of normalized layer thickness within ceramic coating on aluminized steel. Trans. Nonferrous Met. Soc. China 2007, 17, 934-939. [CrossRef]

65. Person, N.L. Fatigue of aluminum alloy welded joints. Welding Research Supplement. Available online: https: / app.aws.org/ wj/supplement/WJ_1971_02_s77.pdf (accessed on 17 April 2021).

66. Ambriz, B.R.; Meamacque, G.; Benhamena, A.; Ruiz, A.; Amrouche, A.; Lopez, V.H. Fatigue crack growth behavior in 6061-T6 aluminum alloy welds obtained by MIEA. 2014. Available online: http://www.gef.es/Congresos/27/pdf/3.pdf (accessed on 15 April 2021).

67. Wasekar, N.P.; Ravi, N.; Babu, P.S.; Krishna, L.R. High-cycle fatigue behavior of micro oxidation coatings deposited on a 6061-T6 Al alloy. Metall. Mater. Trans. A 2010, 41A, 255-265. [CrossRef]

68. Alzoubi, K.; Lu, S.; Sammakia, B.; Poliks, M. Experimental and Analytical Studies on the High Cycle Fatigue of Thin Film Metal on PET Substrate for Flexible Electronics Applications. IEEE Trans. Components Packag. Manuf. Technol. 2010, 1, 43-51. [CrossRef]

69. Asquith, D.; Yerokhin, A.; James, N.; Yates, J.; Matthews, A. Evaluation of Residual Stress Development at the Interface of Plasma Electrolytically Oxidized and Cold-Worked Aluminum. Met. Mater. Trans. A 2013, 44, 4461-4465. [CrossRef]

70. Zhong, D.; Mustoe GG, W.; Moore, J.J.; Disam, J. Finite element analysis of a coating architecture for glass-molding dies. Surf. Coat. Technol. 2001, 146-147, 312-317. [CrossRef]

71. Oskouei, R.H.; Ibrahim, R.N. An investigation on the fatigue behavior of Al 7075-T6 coated with titanium nitride using physical vapour deposition process. Mater. Des. 2012, 39, 294-302. [CrossRef]

72. Shen, D.; Cai, J.; Guo, C.; Liu, P. Evaluation of residual stresses in micro-arc oxidation ceramic coatings on $6061 \mathrm{Al}$ alloy. Chin. J. Mech. Eng. 2013, 26, 1149-1153. [CrossRef]

73. Sadeler, R. Effect of a commercial hard anodizing on the fatigue property of a 2014-T6 aluminum alloy. J. Mater. Sci. 2006, 41, 5803-5809. [CrossRef]

74. Sadeler, R.; Atasoy, S.; Arici, A.; Totik, Y. The fretting fatigue of commercial hard anodized aluminum alloy. J. Mater. Eng. Perform. 2009, 18, 1280-1284. [CrossRef]

75. Mindivan, $\mathrm{H}$. Wear behavior of plasma and HVOF sprayed WC-12Co $+6 \%$ EPFE coatings on AA2024-T6 aluminum alloy. Surf Coat. Technol. 2010, 204, 1870-1874. [CrossRef]

76. Yerramareddy, S.; Bahadur, S. The effect of laser surface treatments on the tribological behavior of Ti-6Al-4V. Wear 1992, 157, 245-262. [CrossRef]

77. Ramalingam, S.; Zheng, L. Coating-substrate interface stress management in wear protection of light alloy components. In Effect of Surface Coatings and Treatments on Wear; Bahadur, S., Ed.; American Society for Testing and Materials: West Conshohocken, PA, USA, 1996; pp. 106-123.

78. Sheng, Q. Tribological and Mechanical Characterization of Thin Polymer Films. Ph.D. Thesis, Northeastern University, Boston, MA, USA, 2013.

79. Bahaideen, F.B.; Saleem, A.M.; Khaleed, H.M.T. Fatigue behavior of aluminum alloy at elevated temperature. Mod. Appl. Sci. 2009, 3, 52-61. [CrossRef]

80. Brammer, A.T. Experiments and Modeling of the Effects of Hear Exposure on Fatigue of 6061 and 7075 Aluminum Alloys. Master's Thesis, University of Alabama, Tuscaloosa, AL, USA, 2013.

81. Mackerle, J. Coatings and surface modification technologies: A finite element bibliography (1995-2005). Model. Simul. Mater. Sci. Eng. 2005, 13, 935-979. [CrossRef]

82. Wei, L.-W.; James, M.N. Numerical modelling of plasticity-induced crack closure for interfacial cracks in bi-material specimens. Eng. Fract. Mech. 2004, 71, 309-327. [CrossRef]

83. Basescu, G.N.; Crismaru, I.V.; Papatoiu Biniuc, C.; Constantin, P.; Lozneanu, M.V.; Munteanu, C. A study on fatigue wear cracks of a 40Cr130 coating in different lubrication conditions. In Proceedings of the International Conference of Scientific Paper, ASASES, Brasov, Romania, 23-25 May 2013.

84. Farley, J.; Wrobel, L.C.; Mao, K. Low cycle fatigue simulation and fatigue life prediction of multilayer coated surfaces. Wear 2010, 269, 639-646. [CrossRef] 
85. Lakkaraju, R.K.; Bobaru, F.; Rohde, S.L. Optimization of multilayer wear-resistant thin films using finite element analysis on stiff and compliant substrates. J. Vac. Sci. Technol. A Vac. Surf. Films 2006, 24, 146-155. [CrossRef]

86. Baragetti, S.; Tordini, F. A review of the fatigue behavior of components coated with thin hard corrosion resistant coatings. Open Corros. J. 2011, 4, 9-17. [CrossRef]

87. Yildiz, F.; Yetim, A.F.; Alsaran, A.; Celik, A.; Kaymaz, I.; Efeoglu, I. Plain and fretting fatigue behavior of Ti6Al4V alloy coated with TiAlN thin film. Tribol. Int. 2013, 66, 307-314. [CrossRef]

88. Bouzakis, K.D.; Vidakis, N.; Leyendecker, T.; Lemmer, O.; Fuss, H.G.; Erkens, G. Determination of the fatigue behavior of thin hard coatings using the impact test and a FEM simulation. Surf. Coat. Technol. 1996, 86-87, 549-556. [CrossRef]

89. Bouzakis, K.D.; Vidakis, N. Prediction of the fatigue behavior of physically vapour deposited coatings in the ball-on-rod rolling contact fatigue test using an elastic-plastic finite elements method simulation. Wear 1997, 206, 197-203. [CrossRef]

90. Bouzakis, K.D.; Maliaris, G.; Makrimallakis, S. Strain rate effect on the fatigue failure of thin PVD coatings: An investigation by a novel impact tester with adjustable repetitive force. Int. J. Fatigue 2012, 44, 89-97. [CrossRef]

91. Otieno, A.; Obikawa, T.; Kamio, K. Numerical modeling for the calculation of temperatures in multiple coated tools. Available online: https://ijme.us/cd_08/PDF/14\%20eng103.pdf (accessed on 15 April 2021).

92. Liu, Y. Finite Element Analysis of Stress Distribution within Metal-on-Metal Joint Replacements. Master's Thesis, Edith Cowan University, Joondalup, WA, Australia, 2012.

93. Kanber, B.; Demirhan, N. Finite element analysis of frictional contact of elastic solids with thin and moderately thick coatings. Turk. J. Eng. Environ. Sci. 2013, 37, 162-177. [CrossRef]

94. Sridhar, K.; Kumar, R.R.; Narasimha, M. Thermal barrier analysis in diesel. Int. J. Mod. Eng. Res. 2013, 3, 1435-1441.

95. Mituletu, I.-C.; Vela, I.; Vela, D.G.; Caramidaru, V.D. A Software Model Proposed for the Contact Stress Calculation of Xylany 1052-Coated Toothed Wheels; Analele Universitatii “Eftimie Murgu": Resita, Romania, 2011; ISSN 1453-7397.

96. Ringsberg, J.W.; Franklin, F.J.; Josefson, B.L.; Kapoor, A.; Nielsen JC, O. Fatigue evaluation of surface coated railway rails using shakedown theory, finite element calculations and lab and field trials. Int. J. Fatigue 2005, 27, 680-694. [CrossRef]

97. Efstathiou, K.; Lontos, A.; Demosthenous, G.; Soukatzidis, F.; Pappa, M.; Michailidis, N. Performance of coated dies in hot extrusion of aluminum. J. Balk. Tribol. Assoc. 2012, 18, 1-17.

98. Peyaut, F.; Seichepine, J.-L.; Coddet, C.; Hertter, M. Finite element modeling of abradable materials-identification of plastic parameters and issues on minimum hardness against coating's thickness. Int. J. Simul. Multidisci. Des. Optim. 2008, 2, $209-215$. [CrossRef]

99. Akin, J.E. Finite Element Analysis Concepts via SolidWorks; World Scientific: Singapore, 2009.

100. Bishop, N.W.M.; Frimlet, M.S.C.; Caserio, A.; Mesa, M.S.C.C. Finite element based fatigue analysis. 1998. Available online: http://web.mscsoftware.com/support/library/conf/amuc98/p01298.pdf (accessed on 15 April 2021).

101. Carlson, R.L.; Steadman, D.L.; Dancila, D.S.; Kardomateas, G.A. Fatigue growth of small corner cracks in aluminum 6061-T651. Int. J. Fatigue 1997, 19, S119-S125. [CrossRef]

102. Navarro, C.; Munoz, S.; Dominguez, J. Fracture mechanics approach to fretting fatigue behavior of coated aluminum alloy components. J. Strain Anal. 2013, 49, 66-75. [CrossRef]

103. Sangkla, T.; Bland, S.; Tuchinda, K. Feasibility study of using TiCN and $\mathrm{CrN}$ thin film coatings to enhance lifetime of grippers used in hard disk drive assembly line. In Proceedings of the World Congress on Engineering, WCE 2011, London, UK, 6-8 July 2011; Volume III.

104. Kolesnikov, V.; Chebakov, M.; Nasedkin, A.; Sukhov, D. Finite element modeling of contact interaction between wheel and rail with three-layered thin coating. Transp. Probl. 2010, 5, 119-124.

105. Sliwa, A.; Dobrzanski, L.A.; Kwasny, W.; Sitek, W. Finite element method application for modeling of PVD coatings properties. J. Achiev. Mater. Manuf. Eng. 2008, 27, 171-174.

106. Sliwa, A.; Tanski, T.; Dziwis, R.; Kwasny, W.; Pancielejko, M. Simulation of internal stresses coatings deposited onto magnesium alloys by use of FEM. Arch. Mater. Sci. Eng. 2013, 64, 28-33.

107. Dobrzanski, L.A.; Zukowsha, L.W.; Sliwa, A.; Mikuta, J. FEM modeling of internal stresses in advanced PVD coatings. J. Achiev. Mater. Manuf. Eng. 2011, 49, 259-268.

108. Tasdemirci, A.; Apalak, M.K. On Elastic Contact Stresses in a Thin Hard Coating/An Elastic Substrate System. 2014. Available online: http:/ / me.erciyes.edu.tr/mkapalak/MKA-PUB/IntConf/00-UMTIK-3.pdf (accessed on 15 April 2021).

109. Majzoobi, G.H.; Farrahi, G.H.; Hardy, S.J.; Pipelzadeh, M.K.; Habibi, N. Experimental results and finite element predictions of the effect of nut geometry, washer and Teflon tape on the fatigue life of bolts. Fatigue Fract. Eng. Mater. Struct. 2005, 28, 557-564. [CrossRef]

110. Baragetti, S.; La Vecchia, G.M.; Terranova, A. Fatigue behavior and FEM modeling of thin-coated components. Int. J. Fatigue 2003, 25, 1229-1238. [CrossRef]

111. Baragetti, S. Fatigue resistance of steel and titanium PVD coated spur gears. Int. J. Fatigue 2007, 29, 1893-1903. [CrossRef]

112. Baragetti, S.; Tordini, F. A numerical study on the fatigue and rolling contact fatigues behavior of PVD-coated steel and titanium spur gears. Eng. Comput. 2011, 27, 127-137. [CrossRef]

113. Ma, Z.S.; Zhou, Y.C.; Long, S.G.; Lu, C. On the intrinsic hardness of a metallic film/substrate system: Indentation size and substrate effects. Int. J. Plast. 2012, 34, 1-11. [CrossRef] 
114. Miao, C.; Qin, F.; Sthur, G.; Chou, K.; Thompson, R. Integrated design and analysis of diamond-coated drills. Comput. Aided Des. Appl. 2009, 6, 195-205. [CrossRef]

115. Ronkainen, H.; Holmberg, K.; Laukanen, A. Coated Surface Design by Modeling and Simulation. 2014. Available online: http:/ / www.miics.net/archive/getfile.php?file=68 (accessed on 15 April 2021).

116. Mount, K.P. Finite Element Analysis of Probe Induced Delamination of a Thin Film at an Edge Interface. Master's Thesis, Virginia Polytechnic Institute and State University, Blacksburg, Virginia, 2002.

117. Madalina, C.; Raluca, M.; Dragos, T.; Adriana, I.; Mihai, L. Finite element modeling of a spark ignition engine piston head, Recent Advances in Fluid Mechanics and Heat \& Mass Transfer. In Proceedings of the 11th International Conferences on Fluid Mechanics \& Aerodynamics (FMA'13), Vouliagmeni, Athens, Greece, 14-16 May 2013.

118. Sroub, J.; Honner, M.; Svantner, M. Numerical models for evaluation thermal conductivity of coatings. Appl. Comput. Mech. 2008, 2, 389-396.

119. Borri, C.; Lavacchi, A.; Fossati, A.; Perissi, I.; Bardi, U. Finite element analysis of thermal fatigue in thermal barrier coatings (TBC). In Proceedings of the COMSOL®Multiphysics Conference, Milan, Italy, 14 October 2009.

120. Hand, R.J.; Field, J.E.; van der Zwaag, S. High modulus layers as protective coatings for "window" materials. In Window and Dome Technologies and Materials; SPIE: Bellingham, WA, USA, 1989; Volume 1112, pp. 120-128.

121. Rahman, M.M.; Ariffin, A.K.; Jamaludin, B.N.; Haron CC, H.C. Fatigue behavior of 6000 series aluminum alloys on cylinder block of a free piston linear engine using total life approach. Jurnal Mekanikal 2006, 21, 1-15.

122. Polonsky, I.A.; Keer, L.M. Numerical analysis of the effect of coating microstructure on three-dimensional crack propagation in the coating under rolling contact fatigue conditions. ASME J. Tribol. 2002, 124, 14-19. [CrossRef]

123. Nilsson, B. Finite Element Procedures for Virtual Tribology. Ph.D. Thesis, University of Gothenburg, Gothenburg, Sweden, 2009.

124. Park, S.; Kapoor, S.G.; DeVor, R.E. Microstructure-level model for the prediction of tool failure in coated WC-Co cutting tool materials during intermittent cutting. ASME J. Manuf. Sci. Eng. 2007, 129, 893-901. [CrossRef]

125. Choi, Y.; Liu, C.R. Performance of nano/mirco CBN particle coated tools in superfinish hard machining. Int. J. Mach. Tools Manuf. 2009, 49, 683-689. [CrossRef]

126. Ribeiro, A.S.; de Jesus, M.P. Fatigue Behaviour of Welded Joints Made of 6061-T651 Aluminum Alloy. 2011. Available online: http:/ / www.intechopen.com/books/howtoreference/aluminium-alloys-theory-and-applications/fatigue-behaviour-of-weldedjoints-made-of-6061-t651-aluminium-alloy (accessed on 15 April 2021).

127. Guler, M.A.; Alinia, Y.; Adibnazari, S. On the contact mechanics of a rolling cylinder on a graded coating. Part 2: Numerical results. Mech. Mater. 2013, 66, 134-159. [CrossRef]

128. Shimpo, R.; Ichikawa, E.; Sugiyama, Y. Mechanical properties of anodic oxide films on aluminum. Surf. Technol. 2003, 54, 794-797. [CrossRef]

129. Ramesh, C.S.; Keshavamurthy, R.; Subramanian, G.G.; Bharath, K.R. High cycle fatigue life prediction of Al6061-TiB2 in-situ composites. Procedia Mater. Sci. 2014, 6, 1455-1469. [CrossRef]

130. Bai, S.; Li, X.; Xie, Z.; Zhou, Z.; Ou, J. A wireless fatigue monitoring system utilizing a bio-inspired tree ring data tracking technique. Sensors 2014, 14, 4364-4383. [CrossRef]

131. Badaruddin, M.; Supriadi, Z.H. Low cycle fatigue properties of extruded 6061-T6 aluminum alloy. J. Phyd. Conf. Ser. 2019, 1198, 032002. [CrossRef] 